\title{
Organic chemistry with lanthanides
}

\author{
Henri B. KAGAN *, Mitsuru SASAKI and Jacqueline COLLIN \\ Laboratoire de Synthèse Asymétrique, UA CNRS 255 , \\ Université Paris-Sud, 91405 Orsay, France
}

\begin{abstract}
Lanthanides are briefly presented in an introductory section. The chemistry induced by divalent lanthanides, esssentially $\mathrm{Sm}$ (II) derivatives, is then discussed. Barbier type reaction and reduction of acid chlorides are mainly considered. Acid chlorides react with $\mathrm{SmI}_{2}$ in various ways, giving rise to interesting organic chemistry.
\end{abstract}

\section{INTRODUCTION}

Lanthanides are members of a large family of elements (Figure 1), located between barium and haf nium in the 6th row of the periodic table. The name of rare earths covers lanthanides and some other elements (yttrium, scandium) usually mixed together in the ores. Lanthanides are no more considered as rare, since industrial processes allow to prepare them in high degree of purity. There is an increasing demand of some lanthanides for modern technology, Rhone-Poulenc $\mathrm{Co}$. is the world leader for production of purified lanthanides. Cerium is the most abundant element in the lanthanide series, followed by lanthanum, neodynium and samarium. Thullium is the rarest lanthanide but it still remains four times more abundant than silver on the earth crust. Apart from cerium (ceric oxidations) lanthanides have been for a long time neglected by organic chemists. However in the last decade there has been a progressive change in that attitude, a recent review (ref.1) summarizes the use of lanthanides in organic synthesis.

$$
\begin{array}{llllllllllllllll}
Z & 57 & 58 & 59 & 60 & 61 & 62 & 63 & 64 & 65 & 66 & 67 & 68 & 69 & 70 & 71 \\
\text { Ln } & \mathrm{La} & \mathrm{Ce} & \mathrm{Pr} & \mathrm{Nd} & \mathrm{Pm} & \mathrm{Sm} & \mathrm{Eu} & \mathrm{Gd} & \mathrm{Tb} & \mathrm{Dy} & \mathrm{Ho} & \mathrm{Er} & \mathrm{Tm} & \mathrm{Yb} & \mathrm{Lu}
\end{array}
$$

\section{Figure 1 The Lanthanum Series}

Several features concerning lanthanides (ref. 2) are of potential interest in organic chemistry:

Main oxidation state : +3 .

oxidations possible by tetravalent lanthanides (mainly cerium).

Reductions possible by divalent lanthanides ( $\mathrm{Eu}, \mathrm{Yb}, \mathrm{Sm}, \mathrm{Tm}$ ).

Rich coordination chemistry, with high coordination numbers.

Lewis acidity, especially for $\operatorname{Ln}($ III) derivatives, with applications to catalysis .

Oxophilicity.

The 4-f orbitals do not much participate to bonding, most of Ln derivatives have a pronounced ionic character.

Redox chemistry with lanthanides involves monoelectronic transfers ( $\mathrm{Ce}(\mathrm{IV}) \rightarrow \mathrm{Ce}$ (III), and $\operatorname{Ln}($ II $) \rightarrow \operatorname{Ln}($ III) ). In the present article we wish to discuss the use of divalent lanthanides in organic chemistry (ref. 4), and then to present some results we have recently obtained.

\section{WHICH DIVALENT LANTHANIDE DERIVATIVES TO USE?}

The standard redox potential values of couple $\operatorname{Ln}^{3+} / \mathrm{Ln}^{2+}$ are: $\mathrm{Eu}=-0.33 \mathrm{~V}, \mathrm{Yb}=-1.35 \mathrm{~V}, \mathrm{Sm}=-1.55 \mathrm{~V}, \mathrm{Tm}=-2.1 \mathrm{~V}$.

By looking to these values one can anticipate the decreasing order of reactivity towards organic compounds: $\mathrm{Tm}>\mathrm{Sm}>\mathrm{Yb}>\mathrm{Eu}$. 
It is impossible to envisage using thullium, which is a very rare element. Some screenings on europium (II) showed that its reducing properties are not very promissing. The most attractive elements for organic chemists are samarium and ytterbium. We devised (ref. 7) a simple and smooth procedure to prepare diiodosamarium and diodoytterbium:

$$
\mathrm{Ln}+\mathrm{ICH}_{2} \mathrm{CH}_{2} \mathrm{I}(\text { in } \mathrm{THF}) \longrightarrow \mathrm{LnI}_{2}+\mathrm{CH}_{2}=\mathrm{CH}_{2}(\mathrm{Ln}=\mathrm{Yb} \text { or } \mathrm{Sm})
$$

These complexes are soluble in THF $(\leqslant 0.1 \mathrm{M})$. The solution can be stored for a long time under nitrogen. It soon appeared that diiodosamarium is the most interesting reagent (ref. 9), and it will be exclusively considered therein. THF solution of diiodosamarium is now commercially available (Alfa Co). Preparation of $\mathrm{Sml} 2$ from samarium metal (powder or ingot, approximate price: 1 to 1.5 dollar $/ g$ ) does not present difficulties if performed under inert atmosphere. The deep green solution turns to yellow after the transformation $\mathrm{Sm}($ II $) \longrightarrow \mathrm{Sm}($ III), giving an easy way to detect the end point of the reaction.

Diiodosamarium is a good starting material for the synthesis of other $\mathrm{Sm}$ (II) derivatives through exchange reactions (refs. 9, 10). For example SmCp2 is easily obtained by addition of $\mathrm{NaCp}$ to a THF solution of $\mathrm{SmI}_{2} . \mathrm{SmCp}_{2}$, which is insoluble in THF, precipitates from the solution.

\section{SUMMARY OF THE MAIN REACTIONS MEDIATED BY $\mathrm{Sml}_{2}$}

During several years we investigated the basic properties of diiodosamarium towards organic compounds (refs. 9, 11-16). Some reactions are indicated in Figure 2.

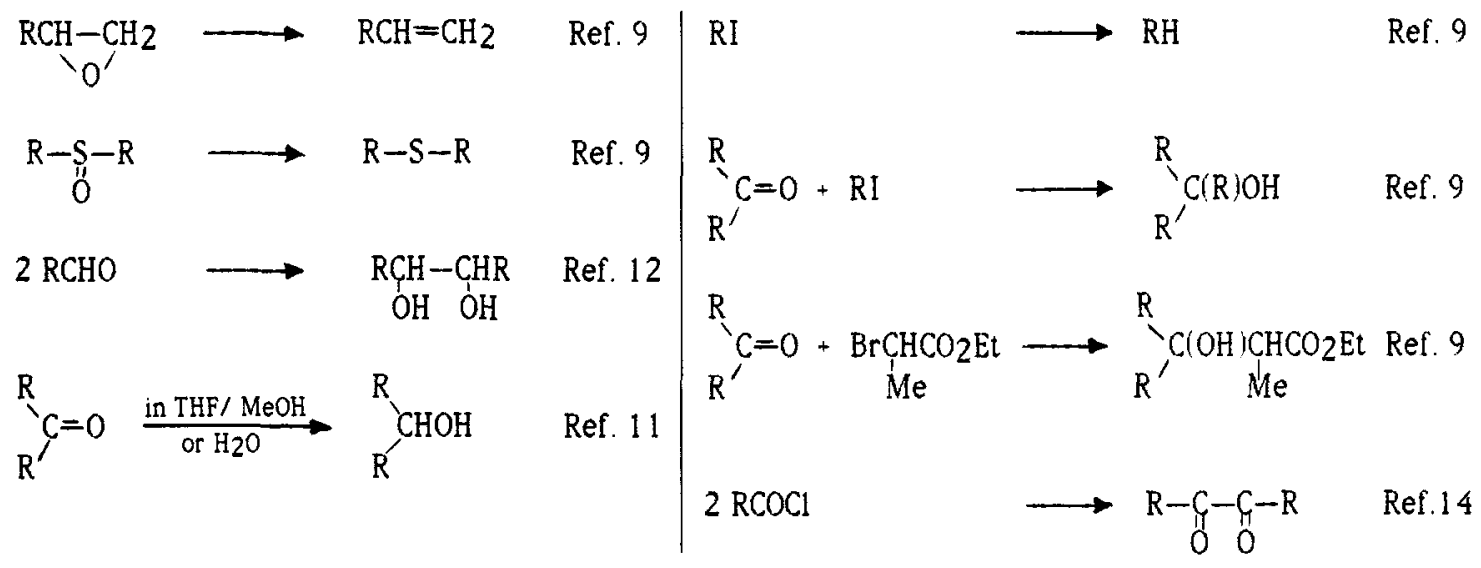

Figure 2

The particular case of $\mathrm{C}-\mathrm{C}$ bond formation by the one pot reaction between aldehydes or ketones and organic halides was called Barbier reaction (the metal of the original Barbier reaction is replaced by SmI2 ). The mechanism of the reaction has been discussed (ref. 12) and is believed to involve a radical in the initial stage :

$$
\mathrm{RX}+\mathrm{SmI} 2 \longrightarrow \mathrm{R}^{\circ}+\mathrm{SmI} 2 \mathrm{X}
$$

Ketones or aldehydes are also electron-acceptors versus $\mathrm{SmI} 2$, as evidenced by the pinacol formation :

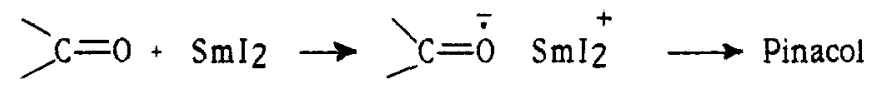

The $\mathrm{C}-\mathrm{C}$ bond formation in the Barbier reaction is not fully elucidated. It could involve organometallic chemistry if the radical $\mathrm{R}^{*}$ is reduced by $\mathrm{SmI} 2$ into RSmI2. All attempts to prepare $\mathrm{RSmI} 2$ from $\mathrm{RX}+\mathrm{SmI} 2$ failed (ref. 9), although such an organometallic species should be stable, since Grignard-like reagents have been prepared from the reaction of samarium metal on alkyl halides (ref. 12). Thus a radical coupling of $R^{*}$ with a ketyl has been proposed. An alternative mechanism could be the direct addition of $R^{*}$ on the carbonyl, followed by a fast reduction of the alkoxy radical. 
The use of 6-bromohexenyl as the organic halide in the Barbier reaction with cyclohexanone mainly gave a cyclized product (ref. 12):<smiles>C=CCCCCBr</smiles><smiles>C=CCCCCC1(O)CCCCC1</smiles>

This finding presumably involves a radical cyclization on the route leading to the product. The intramolecular Barbier reaction has been successfully achieved by Molander (ref. 18). Five and sixmembered rings were obtained from various iodoketones and $\mathrm{SmI} 2$.

The coupling reaction (ref. 14) between acid chlorides leading to $\alpha$-diketones is quite unusual. It has been discussed in the following way (ref. 15):

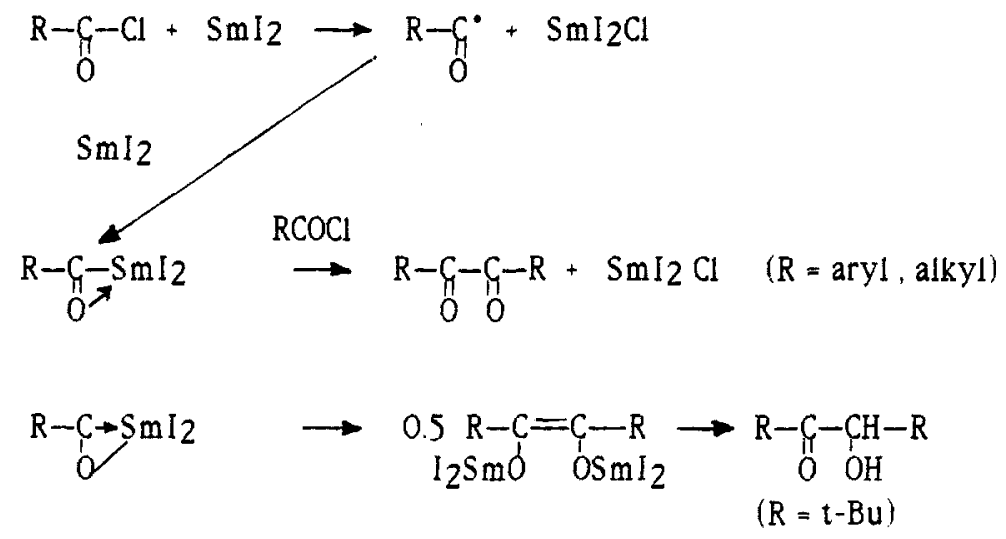

The reaction involves the initial formation of an acyl radical which is believed to be reduced by $\mathrm{Sml} 2$ into a diiodosamarium acyl complex. A mesomeric structure of alkoxycarbene can also be written, by analogy to a complex ( $t$-BuCOLuCp2 ) prepared by Evans (ref. 19). We were unable to isolate the postulated samarium complex, but we devised experiments which can be interpretated as in situ trapping of the acylsamarium species by electrophiles (ref. 15). It involves the addition of a 1:1 mixture of an acid chloride and a ketone to a solution of $\mathrm{Sml} 2$ in $\mathrm{THF}$ :

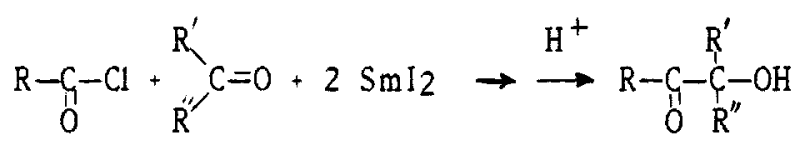

Various ketols have been obtained with isolated yields in the range of 50-70\%, after a few minutes at room temperature.

Diiodosamarium has been used since several years by many groups in Japan, USA or USSR for performing interesting chemistry. The main references till 1986 can be found in a review article (ref. 1).

\section{NEW DEVELOPMENTS INVOLVING ACID CHLORIDES AND $\mathrm{Sml}_{2}$}

The reductive coupling between ketones and acid chlorides mediated by $\mathrm{SmI} 2$ could be a useful way to introduce the side chain of corticosteroids, starting from a 17-ketosteroid:

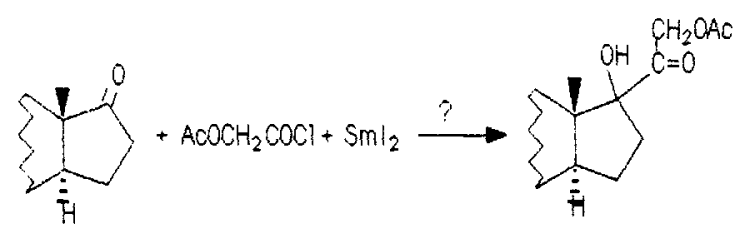


This project needs to examine the reactivity at $\mathrm{C}_{17}$ and to establish the stereochemistry of reactions performed with $\mathrm{SmI} 2$. Dehydroandrosterone (with protected $\mathrm{OH}$ ) was taken as a model Several reactions were successfully achieved in the presence of $\mathrm{SmI} 2$ (Figure 3).

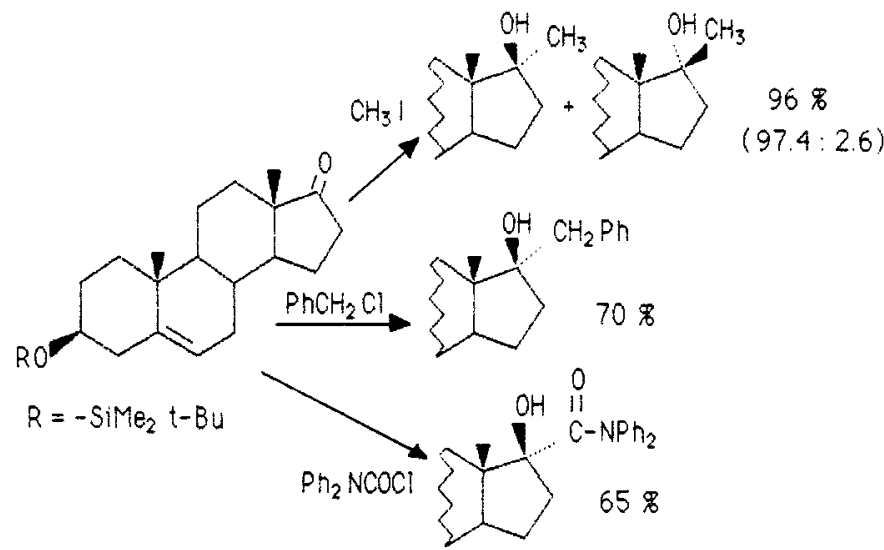

Figure 3 Reactions performed in THF at room temperature in the presence of 2 eq. of $\mathrm{SmI} 2$

Barbier reaction with methyl iodide gave a tertiary alcohol attacking from usual $\alpha$-side at $C_{17}$ in a quantitative yield. The stereochemistry was established by comparison with an authentic sample. The $17 \mathrm{\beta OH} / 17 \alpha \mathrm{OH}$ ratio $(97: 3)$ is almost the same as that seen in the corresponding Grignard reaction performed with MeMgI. The reactions of $\mathrm{PhCH}_{2} \mathrm{OCH}_{2} \mathrm{COCl}$ and $\mathrm{MeOCH}_{2} \mathrm{COCl}$ were then investigated on the same steroid. The structures of the isolated products were not the expected ones. The products are devoid of carbonyl group (Fig. 4). The reaction is quite general and

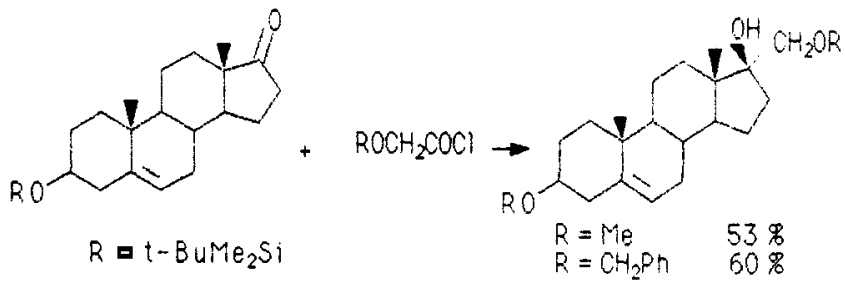

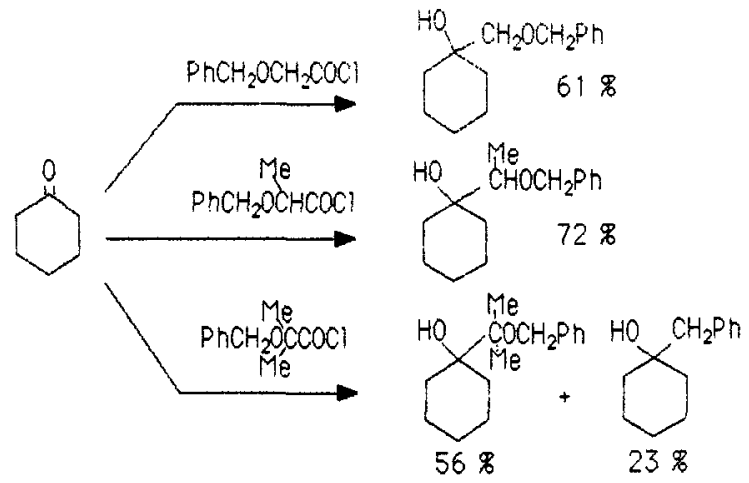

Figure 4

can give various kinds of glycol monoethers (ref. 20).The process is explained by a fast decarbonylation, presumably at the stage of the acyl radical :

$$
\begin{aligned}
& \mathrm{ROCH}_{2} \mathrm{COCl}+\mathrm{SmI}_{2} \rightarrow \mathrm{ROCH}_{2} \dot{\mathrm{C}}=0+\mathrm{SmI}_{2} \mathrm{Cl} \\
& \downarrow \\
& \mathrm{ROCH}_{2} \mathrm{SmI} 2 \underset{\mathrm{SmI} 2}{\leftarrow} \mathrm{ROCH}_{2}^{\circ}+\mathrm{CO}
\end{aligned}
$$


The driving force for the decarbonylation is the formation of a stabilized alkoxy radical. The initial formation of an acyl radical has been assumed in all the reactions involving an acid chloride and $\mathrm{SmI} 2$ (ref. 15). It was interesting to try to trap intramolecularly such intermediates in a suitable model. For this purpose some salicylic acid derivatives were prepared (Fig. 5). The acid chlorides fastly react with SmI2 to give products more complex than expected, since an additional cyclopropanol ring is formed (ref. 21). The yields in crude material are excellent, isolated yields in pure compounds are in the range of 50-60\% because of the instability of the products which partly decompose during the isolation procedure (flash-chromatography). Structures were established by spectroscopic methods ( $1 \mathrm{H}$ and $13 \mathrm{C} \mathrm{NMR,} \mathrm{IR} \mathrm{and} \mathrm{MS).} \mathrm{In} \mathrm{the} \mathrm{two} \mathrm{first} \mathrm{examples} \mathrm{of} \mathrm{Figure} 5$ only one stereoisomer is obtained, in the last case the product is a 10:1 mixture of exo/endo epimers.<smiles>C=CCOc1ccccc1C(=O)Cl</smiles>

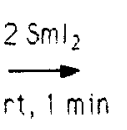<smiles>OC12CC1COc1ccccc12</smiles>

518<smiles>C=C(C)COc1ccccc1C(=O)Cl</smiles><smiles>CC12CC3(CC3)C1(O)C2</smiles><smiles>[AsH2]</smiles><smiles>CC=CCOc1ccccc1C(=O)Cl</smiles><smiles>OC12CC1CC1COc3ccccc3C12O</smiles><smiles>C=C1COc2ccccc2[Te]1=O</smiles><smiles>O=C1c2ccc(cc2)OCC1CSS</smiles><smiles>C=CCOc1ccccc1CO</smiles>

Figure 5 Cyclization in THF at room temperature in presence of 2 eq. of $\mathrm{Sml}_{2}$

The mechanism proposed for the reaction is indicated in Figure 6 . The acyl radical has a high tendency to cyclize, as shown recently by Zard (ref, 22). It has been produced by the Barton method of photolysis of 5 acyl xanthates (ref. 23). The last step of Figure 6, namely the intramolecular addition of an organosamarium species, is well supported by experiments of Imamoto et al.(ref. 24). These authors prepared cyclopropanols by treatment of iodomethylketones of type R-C(O)-CH(R)$\mathrm{CH} 21$ ( in situ produced) by $\mathrm{SmI} 2$. The intramolecular carbene addition written in Figure 6 cannot fully be excluded but is unprecedented in lanthanide chemistry. More studies are needed to fully confirm mechanism of the reaction and to see the scope of this unusual transformation.

\section{CHEMISTRY MEDIATED BY SMCp}

There are evidences of a good stability of $t-B u C O L u C C_{2}$ (ref. 19). Cyclopentadienyl ligands should give an increased stability (by respect to iodide) to lanthanide complexes. Indeed we were able to produce at $-20^{\circ} \mathrm{C}$ a stable acylsamarium complex from pivaloyl chloride and two equivalents of $\mathrm{SmCp} 2$ (ref. 25). This complex, kept in THF solution at $-20^{\circ} \mathrm{C}$, further reacts with aldehydes to give $\alpha$-ketols. This observation encouraged us to try to prepare organosamarium complexes from organic halides and $\mathrm{SmCp}_{2}$, complexes that we did not previously obtain with $\mathrm{Sml} 2$. We discovered that benzyl chloride as well as other benzylic halides reacts at room temperature with SmCp2 (insoluble in THF), forming dark-brown solution of organosamarium complexes (ref. 26). These complexes are attacked by various electrophiles ( $\mathrm{D}_{2} \mathrm{O}$, aldehydes, acid chlorides) to give the expected products. For example

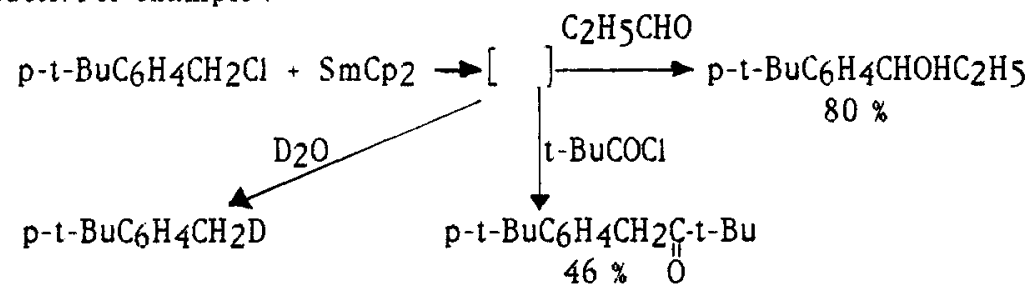


These observations are interesting, not only for synthetic applications in organic chemistry, but also for the possibility to develop a new route to organosamarium complexes with a carbon-samarium bond. Indeed organolanthanides have many unexpected properties, such as to promote $\mathrm{CH}$ activation of alkanes (ref. 27). Lanthanide hydrides ( (C5Mes) $2 \mathrm{LnH}$ ) are powerful homogeneous catalysts for hydrogenation of olefins (ref. 28), and can be formed by hydrogenation of the corresponding alkyllanthanides.

Dicyclopentadienylsamarium has been compared to $\mathrm{Sml}_{2}$ in Barbier reactions (ref. 29). It gives much faster reactions than $\mathrm{SmI} 2$ does.

\section{CONCLUSION}

Divalent lanthanides, especially diiodosamarium, are able to promote many types of organic reactions. Very often reactions are quite fast and selective. It is difficult to analyze the mechanistic details, because radical intermediates generate in the presence of an electron donor. Chemistry starting from acid chloride is quite unusual and deserves further investigation.

\section{REFERENCES}

(1) Kagan, H. B. and Namy, J. L. , Tetrahedron, 42, 6573 (1986).

(2) For a review on organometallic chemistry of lanthanides see (ref. 3 ).

(3) Marks. T. J. and Ernst, F. D., in "Comprehensive Organometallic Chemistry", Wilkinson. G. Ed., Pergamon Press (1982), vol. 3, 173.

(4) The preparations and properties of divalent lanthanide derivatives were reviewed (refs. 5,6).

(5) Kagan, H. B. and Namy, J. L., in "Handbook on the Physics and Chemistry of Rare Earths", Gschneidner, K. A. Jr and Eyring. L. eds. North Holland. Amsterdam, 1984. 550.

(6) Evans. W. J., Polyhedron, 6, 803 (1987).

(7) Namy, J. L.; Girard, P. and Kagan, H. B., Nouv, J. Chim, , 1, 5 (1977)

(8) Namy, J. L. ; Girard, P. ; Kagan, H. B. and Caro, P., Nouv . Chim., 5479 (1981).

(9) Girard, P. ; Namy, J. L. and Kagan, H. B. , J Am. Chem. Soc 102, 2693 (1980).

(10) Evans. W.J. ; Grate, J.W. ; Choi, H. W. ; Bloom, I. ; Hunter, W. E. and Atwood, J. L. , J Am. Chem. Soc, 107, $941(1985)$.

(11) Kagan, H. B. : Namy, J. L. and Girard, P. . Tetrahedron, 37 (Suppl. 1),175 (1981).

(12) Souppe, J. ; Namy, J.L. and Kagan, H. B. Tetrahedron Lett 24, 765 (1983).

(13) Souppe, J. ; Danon, L.: Namy, J. L. and Kagan H. B. .J. Organomet. Chem, 250, 227 (1983).

(14) Girard. P. ; Couffignal, R. and Kagan, H. B., Tetrahedron Lett. 22, 3959 (1981),

(15) Souppe, J.; Namy, J. L. and Kagan, H. B. , Tetrahedron Lett, 25, 2869 (1984).

(16) Souppe, J.; Namy, J. L. and Kagan, H. B. , Tetrahedron Lett, 23, 3497 (1982).

(17) Evans, D. F.; Fazakerley, G. V. and Phillips, R. F., I. Chem. Soc. Chem. Commun, 244 (1970).

(18) Molander, G. and Etter, J.B., J. Org. Chem. 51 , 1778 (1986).

(19) Evans,W.J.:Wayda,A.L.; Hunter, W. E. and Atwood, J.L., J. Chem. Sac. Chem. Commun, $706(1981)$

(20) Sasaki. M. ; Collin, J. and Kagan, H. B., sub mitted to publication.

(21) Sasaki, M. ; Collin, J. and Kagan, H. B. , unpublished results.

(22) Delduc, P.; Tailhan,C. and Zard, S. Z , . Chem. Soc. Chem. Commun, 308 (1988).

(23) Barton, D. H. R.; George, M. V. and Tomoeda, M. J. Chem Sac, 1967.(1962).

(24) Imamoto, T. and Takiyama. N., Tetrahedron Lett, 28, 1307 (1987).

(25) Namy, J. L. ; Collin, J. and Kagan, H. B. , unpublished results.

(26) Collin, J.; Namy, J.L.; Bied, C. and Kagan H. B., Inorg. Chim. Acta 140, 29 (1987).

(27) Watson P. and Parshall, G. W. , Acc. Chem. Res., 18, 51 (1985), and references quoted therein.

(28) Jeske, G. ; Lauke, H. ; Mauermann, H.; Schumann, H. and Marks, T. J., J. Am. Chem. Soc., 107 $8111(1985)$.

(29) Namy, J. L.; Collin, J. ; Zhang, J. and Kagan, H. B., J. Organomet. Chem, 328, 81 (1987). 